\title{
Studies on photocatalytic behavior under UV and sunlight using nano- $\mathrm{TiO}_{2}$
}

\author{
B. Bharati* and Chandana Rath \\ School of Materials Science and Technology, Indian Institute of Technology (BHU), Varanasi \\ *Email: bharatib47@gmail.com
}

$\mathrm{TiO}_{2}$ semiconductor designates as a promising oxide material from both fundamental as well as from their potential applications in various devices [1-3]. Nowadays main issues of the universe are conservation of energy and pollution control. In this contest, various sizes and shapes of $\mathrm{TiO}_{2}$ can be suitable oxide materials which have been synthesized by chemical technique where nanoparticles can be ensured. In this work, we have synthesized $\mathrm{TiO}_{2}$ nanoparticles through one of the chemical route like sol-gel and post calcined at $500^{\circ} \mathrm{C}$. Sample characterized by X-ray diffraction, Raman spectroscopy show pure anatase phase (Figure 1). Raman results also support the XRD results.

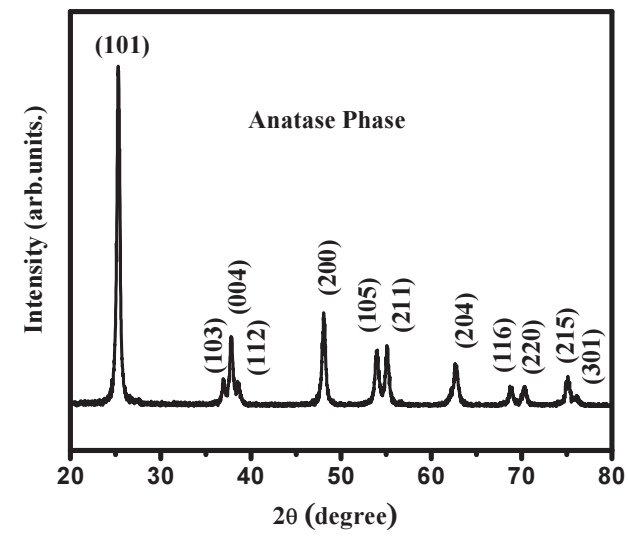

Figure 1: XRD pattern of $\mathrm{TiO}_{2}$ synthesized by sol gel route

Photocatalytic behavior of different organic dyes of concentration $5000 \mathrm{ppm}$ is studied by using $20 \mathrm{mg}$ of $\mathrm{TiO}_{2}$ nanoparticles under UV-radiation as well as under sunlight.

While under UV-radiation, degradation of $100 \%$ of Methylene Blue (MB) takes $180 \mathrm{~min}$, Congo Red (CR) takes 120 min and Rhodamine B (RhB) takes $180 \mathrm{~min}$, under sunlight, $\mathrm{MB}$ takes $90 \mathrm{~min}$, CR takes $45 \mathrm{~min}$ and RhB takes $180 \mathrm{~min}$ (Figure $2)$. From the results, it is concluded that the synthesized nano $\mathrm{TiO}_{2}$ sample is more active under sunlight for $\mathrm{MB}$ and $\mathrm{CR}$. By using sunlight which is a source of abundant energy, degradation of dyes, can be done easily rather than using UV-light. Thus $\mathrm{TiO}_{2}$ is found to be an efficient catalyst for degradation of organic pollutant using sunlight.

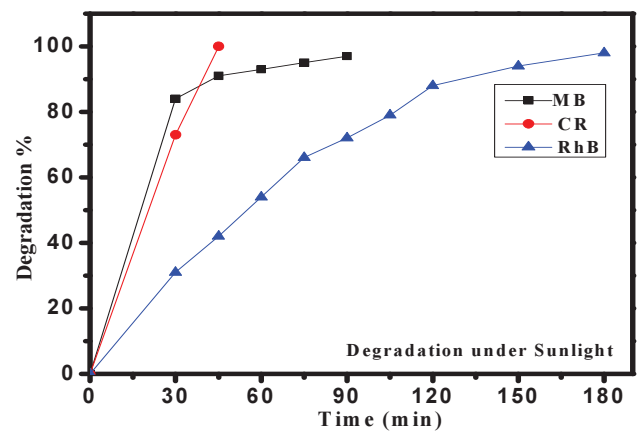

Figure 2: Effect of irradiation time on photo degradation under sunlight

\section{References}

1. C Rath et al., J phys. 42 (2009) 205101

2. P Mohanty et al., J Magn. Magn. Mat. 355 (2014) 240-24533

3. S Erdemoglu et al, J. Hazardous Materials 155 (2008) 469-476

4. W Zhou et al., J. Phys, D: Appl. Phys 43 (2010) 035301 .

5. Z Jiao et al., Sci. Rep.3, 2720 (2013) srep02720 